\title{
Perfil das prescrições de antibioticoterapia em uma unidade de terapia intensiva adulto de um hospital de referência cirúrgica no estado do maranhão
}

\author{
Profile of antibiotics prescription in an adult intensive care unit at a surgical reference \\ hospital in the state of Maranhão
}

Perfil de prescripción de antibióticos en una unidad de cuidados intensivos adultos de una hospital de referencia quirúrgica en el estado de Maranhão

Francisco Alves Lima Júnior ${ }^{1,2,5}$, Emilly Matias Souza Vieira1', Bruna Santos da Silva ${ }^{1}$, Tessy Dias de Araújo ${ }^{1}$, Thays Gouveia Miranda dos Reis ${ }^{1}$, Jonas de Melo Miranda ${ }^{3}$, Karla Vanessa Morais Lima $^{4}$, Raquel Machado Borges ${ }^{3,4}$, Denilson da Silva Lima ${ }^{4}$, Felype Hanns Alves de Medeiros ${ }^{2}$, Andreia Nappo Dalla Libera Rego de Medeiros $^{5}$, Lilian Natália Ferreira de Lima ${ }^{1}$, Mauro de Souza Pantoja².

\section{RESUMO}

Objetivo: descrever o perfil dos principais antibióticos prescritos em uma Unidade de Terapia Intensiva UTI Adulto de um Hospital de Referência Cirúrgica no Estado do Maranhão. Métodos: Trata-se de um estudo exploratório, quantitativo e documental. No qual, analisaram-se os prontuários de clientes admitidos no setor da UTI, de um hospital de referência em cirurgias ambulatoriais, entre o período de novembro de 2016 e janeiro de 2018, no qual, os dados foram tabulados através do programa Microsoft Office Excel®. Resultados: De novembro de 2016 até janeiro de 2018, evidenciou-se 220 pacientes internados na UTI Adulto com uso de antibióticos. Foram prescritos durante esse período 574 antibióticos para os 220 pacientes. As classes de antibióticos mais frequentes nas prescrições analisadas foram as Cefalosporinas com 201 (35\%), seguida dos Carbapenêmicos com 120 (20,9\%) e pelos Glicopeptídeos com 96 (16,7\%), sendo que, no presente estudo, as Cefalosporinas tiveram como principal representante a Cefepima. Conclusões: Nota-se ser de suma importância o saber a respeito do uso de antibióticos, visto que esses exercem ampla atuação nas unidades hospitalares, em especial as unidades de terapia intensiva sendo interligada diretamente a resistência bacteriana que é um atual problema de saúde pública a nível mundial.

Palavras-chave: Prescrições de Medicamentos, Antibióticos, Unidade de Terapia Intensiva.

\footnotetext{
ABSTRACT

Objective: to describe the profile of the most prescribed antibiotics in an Adult Intensive Care Unit of a Surgical Reference Hospital in the State of Maranhão. Methods: This is an exploratory, quantitative and documentary study. The medical records of patients admitted to the ICU sector of an outpatient surgical reference hospital from November 2016 to January 2018 were analyzed. Data were tabulated using the Microsoft Office Excel® program. Results: From November 2016 to January 2018, 220 patients admitted to the ICU with antibiotics were observed. During this period 574 antibiotics were prescribed to 220 patients.

${ }^{1}$ Universidade Estadual do Tocantins - UNITINS, Palmas-TO.

'Universidade do Estado do Pará, Belém-PA.

${ }^{3}$ Faculdade de Ciências Médicas e Jurídicas, Faculdade do Bico do Papagaio FACMED/FABIC, Augustinópolis-TO;

${ }^{4}$ Faculdade de Imperatriz - FACIMPM WYDEN, Imperatriz-MA.

${ }^{5}$ Universidade Centro Universitário do Maranhão - CEUMA, Campus Imperatriz-MA.

*E-mail: francisco.enfdotrabalho@gmail.com
} 
The most frequent antibiotic classes in the prescriptions analyzed were Cephalosporins with 201 (35\%), followed by Carbapenems with $120(20.9 \%)$ and Glycopeptides with $96(16.7 \%)$. In the present study, Cephalosporins were mainly represented by Cefepime. Conclusions: It is important to know about the use of antibiotics, since they are widely used in hospitals, especially ICUs, thus directly linked to bacterial resistance that is a current health problem worldwide.

Keywords: Drug Prescriptions, Antibiotics, Intensive Care Unit.

\section{RESUMEN}

Objetivo: describir el perfil de los principales antibióticos prescritos en adultos unidad de cuidados intensivos de una Hospital quirúrgico referencia en el estado de Maranhão. Métodos: se trata de un estudio exploratorio, cuantitativo y documental. Que, analizados los informes médicos de los clientes ingresados en el sector de ICU, una referencia de cirugía ambulatoria de hospital, entre el período de noviembre de 2016 y de 2018 de enero, en que, los datos fueron tabulados a través de la Microsoft Office Excel®. Resultados: Desde noviembre hasta enero 2016 2018, fue de 220 pacientes del adulto de la ICU con el uso de antibióticos. Durante este período fueron prescritos antibióticos para los 574220 pacientes. Las clases de antibióticos más frecuentes en las recetas analizadas fueron las cefalosporinas con 201 (35\%), seguidas por el Carbapenêmicos con $120(20,9 \%)$ y para glicopéptidos con $96(16,7 \%)$ y, en el presente estudio, las cefalosporinas jefe representante a Cefepime. Conclusiones: Nota a ser de suma importancia el conocimiento sobre el uso de antibióticos, ya que estos ejercen amplia experiencia en unidades hospitalarias, particularmente unidades de cuidados intensivos se conecta directamente a la resistencia bacteriana que es una actual problema de salud pública en todo el mundo.

Palabras clave: Prescripción Medicamentos, Antibióticos, Cuidados Intensivos.

\section{INTRODUÇÃO}

Toda matéria que é produzida naturalmente ou por síntese que seja capaz de combater microrganismos denomina-se antibiótico. A partir dos os estudos de Paul Ehrlinch houve a primeira aparição de substâncias que apresentavam essas características. Com o surgimento dos antibióticos houve uma remodelação no tratamento de pacientes com doenças infecciosas causadas por microrganismos, onde, a aplicação dos antibióticos trouxe benefícios significativos em relação à morbimortalidade de infecções por bactérias. Por outro lado, o uso irracional no decorrer dos anos trouxeram algumas complicações, principalmente em relação à criação de bactérias resistentes a antibioticoterapia (FERREIRA VM, et al., 2016; COSTA ALP e SILVA JÚNIOR ACS, 2017).

O antibiótico é um dos medicamentos mais utilizados dentro de Unidades de Terapia Intensiva (UTI), no entanto, o uso prolongado e contínuo favorece o aparecimento de micróbios resistentes, isto por meio do processo de adaptação do mesmo, quanto ao uso em tempo prolongado, destas substâncias. Segundo a Organização Mundial da Saúde - OMS, aproximadamente 50\% das prescrições de antibióticos realizadas a nível internacional são executadas de maneira incorreta, para tanto, ao serem utilizados os antibióticos recebem acompanhamento desde a sua aquisição aos resultados medicinais obtidos (FERREIRA VM, et al., 2016; SILVA CDR e SILVA JÚNIOR M, 2015).

O tratamento realizado através de antibióticos provoca de forma seletiva os surgimentos de bactérias resistentes a este fármaco, o uso inadequado dessa droga pode impossibilitar a eficácia do tratamento a logo prazo. Em consequência disso, expõe em risco à vida humana, tornando-se logo, um problema de saúde pública. Desta forma, transfigura-se o pontapé inicial para outros problemas de saúde pública como as infecções hospitalares, assim, ocasionando um dano gigantesco ao orçamento dos sistemas de saúde, seja público ou privado. Essa situação é caracterizada pela associação de elementos como: pacientes com mecanismos imunológicos deficientes, uso ininterrupto e inapropriado de antibióticos e ocorrência de 
infecções hospitalares por bactérias altamente resistentes e nocivas à saúde. (SOUZA FC, et al., 2017; COSTA ALP e SILVA JUNIOR ACS, 2017; PINTO IC, et al., 2018).

Levando em consideração que um hospital é um órgão composto por vários setores, dividido por tarefas e funcionalidades com objetivo de tratar seus pacientes e fechar diagnóstico, a UTI é o local que mais oferece perigo de infecções hospitalares relacionados a bactérias resistentes, visto que, é o setor que o fluxo e demanda de antibióticos é maior, logo, é evidente que precisa existir o uso correto e fracionado deste medicamento, para que as taxas de resistência microbiana e infecção hospitalar sejam diminuídas (NEVES C e COLET C, 2015).

Eentende-se que é um problema de saúde pública eminente a nível mundial, uma vez que, essa classe é uma das mais utilizadas, responsável por cerca de $50 \%$ das despesas hospitalares relacionadas a medicamentos, resultando em gastos desnecessários, má distribuição de medicamentos, desperdícios financeiros em longa escala e a assistência totalmente prejudicada do paciente (FERREIRA VM, et al., 2016; NEVES C e COLET C, 2015; ANVISA, 2017).

Apesar de existir uma gama expressiva de literaturas que aponte os benefícios do uso correto de antibióticos, várias políticas promovidas pelas Comissões de Controle de Infecção Hospitalar $(\mathrm{CCIH})$ e uma luta constante contra o mau uso destes medicamentos, encontra-se grande dificuldade sobre a aceitação destas pelos profissionais de saúde (SOUZA FC, et al., 2017).

A OMS buscou quantificar e qualificar cientificamente antimicrobianos, determinar a utilização de antibióticos por unidade de interação através da metodologia da Anatomical Therapeutic Chemical Dose Definida Diária (ATC/DDD) permitindo estabelecer um perfil para comparação entre as instituições, fornecendo uma ferramenta importante para a CCIH (SOUZA FC, et al., 2017).

É de extrema relevância o uso inteligente de antibióticos, uma vez que, impossibilita o surgimento exacerbado de bactérias resistentes. Restaurando a ordem hospitalar, diminuindo o quadro de infecções hospitalares, desperdício de medicamentos e possibilitando uma assistência de qualidade ao paciente (SANTOS RG, et al., 2016).

Em vista da situação exposta, o objetivo do presente estudo é descrever o perfil dos principais antibióticos prescritos em uma Unidade de Terapia Intensiva Adulto de um Hospital de Referência Cirúrgica no Estado do Maranhão.

\section{MÉTODOS}

Trata-se de um estudo exploratório, sendo realizado um corte transversal com uma abordagem quantitativa para tratamento dos dados obtidos, sendo o mesmo de cunho documental. Analisaram-se os prontuários de clientes admitidos no setor da UTI, de um hospital de referência em cirurgias ambulatoriais, entre o período de novembro de 2016 e janeiro de 2018, no qual, foram selecionados os registros datados de tal período analisado, sendo descartados da pesquisa os demais registros que pertenciam a outros setores da instituição ou com divergência no período analisado.

Utilizou-se para fim de coleta de dados fichas de controle de prescrição de antibióticos mantidos sob responsabilidade do Serviço de Controle de Infecção hospitalar - SCIH já tabuladas em banco de dados, não tendo a exposição de identificação dos pacientes, que segundo a Resolução 510/2016 do Conselho Nacional de Saúde dispensa o envio da pesquisa para o Comitê de Ética e Pesquisa - CEP.

Os dados foram tabulados através do programa Microsoft Office Excel®, sendo os mesmos graficamente e estatisticamente representados, e correlacionados com a literatura vigente acerca da temática difundida.

\section{RESULTADOS E DISCUSSÃO}

De novembro de 2016 até janeiro de 2018, o sistema utilizado pelo hospital indicou 220 pacientes internados na UTI Adulto com uso de antibióticos, tendo $50 \%$ do sexo masculino e $50 \%$ do sexo feminino, 
com média de idade em 55 anos (mínimo de 11 e máximo de 102 anos), sendo que 50 pacientes continham idade maior que 60 anos, ou seja, eram idosos.

Foram prescritos durante esse período 574 antibióticos para os 220 pacientes. As classes de antibióticos mais frequentes nas prescrições analisadas foram as Cefalosporinas com 201 (35\%), seguida dos Carbapenêmicos com 120 (20,9\%) e pelos Glicopeptídeos com 96 (16,7\%).

Em comparação ao estudo de Ferreira e seus colaboradores em 2016, os beta-lactâmicos foram os mais prescritos no ambiente hospitalar, predominando a classe das Cefalosporinas de primeira geração com a cefazolina e terceira geração, com a ceftriaxona. Já no presente estudo, as Cefalosporinas tiveram como principal representante a Cefepima (FERREIRA VM, et al., 2016).

A Cefepima é prescrita comumente em casos de infecções urinárias, intra-abdominais e pneumonias, além de septicemias e febre em neutropênicos (MELO VV, et al., 2012). Ela pode ser um fator de risco modificável no desenvolvimento da disfunção neurológica de forma aguda, principalmente em pacientes com problemas de insuficiência renal. Recomenda-se uso de antibióticos alternativos em pacientes com risco, em razão do potencial para surgimento de resistência bacteriana com escolhas antibióticas prejudiciais (PAYNE LE, et al., 2017).

De acordo com os registros encontrados observa-se uma prevalência no uso da Cefepima, Vancomicina, Ceftriaxona e mipenem + Cilastatina, respectivamente, sendo suas devidas representações expressas na Tabela 1.

Tabela 1 - Antibióticos prescritos a pacientes internados na UTI Adulto em um hospital de referência cirúrgica do Maranhão, no período de dezembro de 2016 a janeiro de 2018.

\begin{tabular}{ccc}
\hline ANTIBIÓTICOS & N & $\%$ \\
\hline Cefepima & 113 & 19,6 \\
Vancomicina & 96 & 16,7 \\
Ceftriaxona & 83 & 14,4 \\
Imipenem + Cilastatina & 75 & 13 \\
Meropenem & 45 & 7,8 \\
Piperacilina + Tazobactan & 33 & 5,7 \\
Clindamicina & 30 & 5,2 \\
Metronidazol & 28 & 4,8 \\
Levofloxacino & 27 & 4,7 \\
Sulfato de Polimixina & 10 & 1,7 \\
Fluconazol & 8 & 1,3 \\
Oxacilina Sódica & 6 & 1 \\
Ciprofloxacino & 4 & 0,6 \\
Ceftazidima & 3 & 0,5 \\
Gentamicina & 2 & 0,3 \\
Ampicilina Sódica & 2 & 0,3 \\
Neomicina + Bacitracina & 2 & 0,3 \\
Colagenase com & 2 & 0,3 \\
Cloranfenicol & & \\
Culfametoxazol/Trimetoprin & 2 & 0,3 \\
Cefalotina & 2 & 0,3 \\
Azitromicina & 1 & 100 \\
TOTAL & 574 &
\end{tabular}

Fonte: Lima Júnior FA, et al., 2019.

A Vancomicina, segundo antibiótico mais prescrito, o medicamento teve seu uso disseminado, no entanto, foi bastante prescrito para o tratamento de sepses, sendo prescrito 56 vezes. Neves $\mathrm{C}$ e Colet $\mathrm{C}$ (2015) salientam que enterococos resistentes a esse medicamento estão sendo encontrados em maior frequência, principalmente em UTI. 
A Ceftriaxona é bastante utilizada em pneumonias, infecções urinárias, meningites, bacteremias, gonorreia, sífilis, além de infecções intra-abdominais e ginecológicas, que deve ser usada em associação com anaerobicidas (SILVA TFA, et al., 2014).

As pneumonias apresentaram um valor acentuado na pesquisa, sendo diagnosticada 149 vezes entre as classes de pneumonia $(39,5 \%)$, pneumonia associada à ventilação mecânica (PAV) $(30,8 \%)$, pneumonia nosocomial $(20,1 \%)$, pneumonia adquirida na comunidade (PAC) (6\%), pneumonia aspirativa (2\%) e intersticial difusa (1,3\%) como apresentado no Gráfico 1.

Gráfico 1 - Uso da Cefepima, Vancomicina e Ceftriaxona nos principais tipos de Pneumonia em pacientes internados na UTI Adulto em um hospital de referência cirúrgica do Maranhão, no período de dezembro de 2016 a janeiro de 2018.

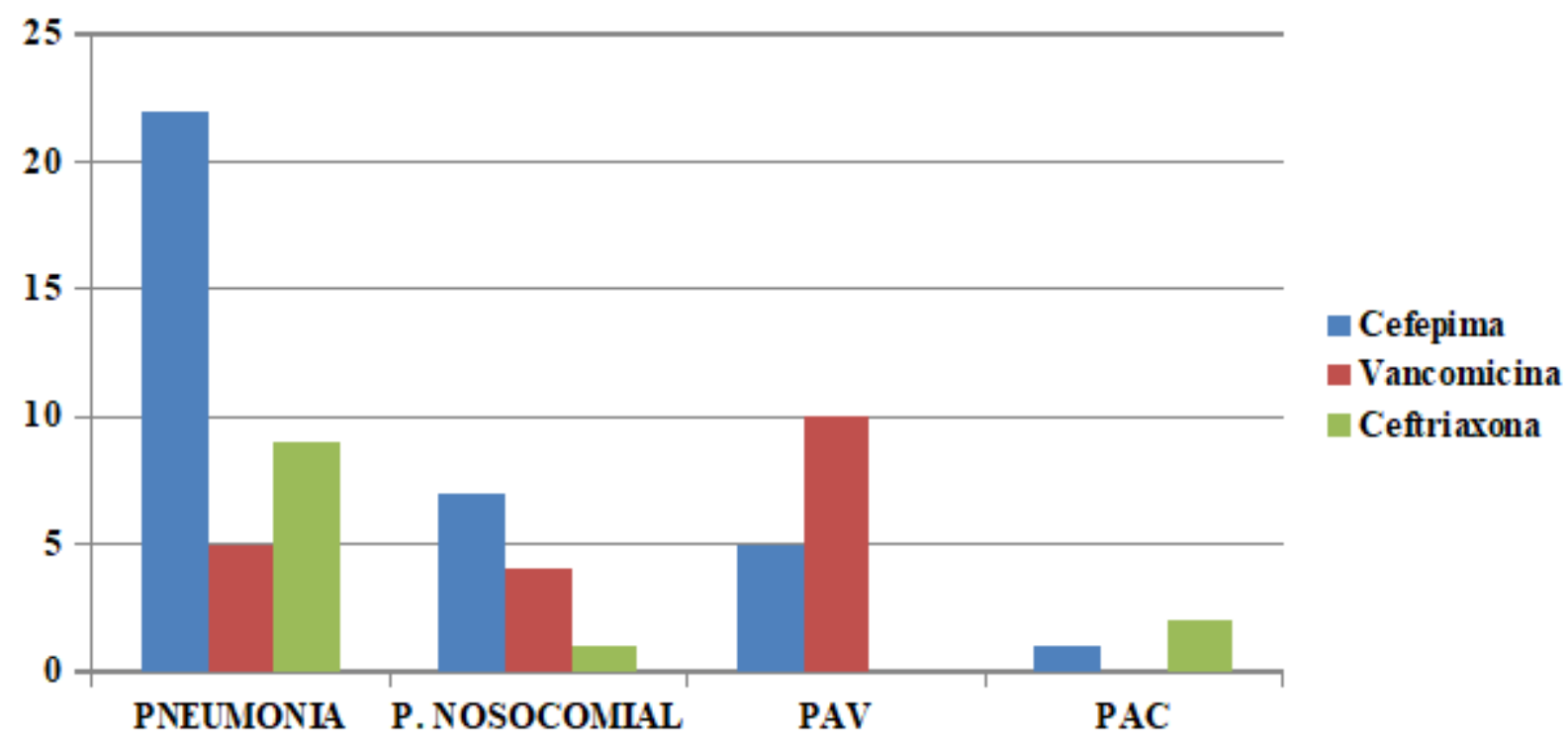

Fonte: Lima Júnior FA, et al., 2019.

Observa-se no gráfico, que dentre os antibióticos analisados, a Cefepima é bastante utilizada na pneumonia simples, no entanto, é ultrapassada pela Vancomicina no tratamento de PAV. A Ceftriaxona apresenta valores baixos no tratamento de Pneumonia Nosocomial e não foram encontrados uso dela para PAV.

A associação de Imipenem+Cilastatina tem seu principal uso em infecções nosocomiais por microrganismos multirresistentes, em especial as causadas por Citrobacter freundii, Acinetobacter spp e Enterobacter spp (MELO VV, et al., 2012).

Observou-se na análise de dados que a combinação é bastante aplicada em PAV, sepses, choques sépticos e quando não há um diagnóstico, podendo levar a uma resistência bacteriana mais facilmente.

O Meropenem Teve seu uso diversificado no presente estudo, notando-se aplicação deste para PAV, abscessos, sepses, além da indicação para casos sem diagnósticos.

Da classe das penicilinas, a associação de Piperacilina+Tazobactam tem indicação em pacientes adultos para infecções de trato respiratório superior, trato urinario, intra-abdominais, sepse bacteriana, infecções de pele e tecidos moles entre outras patologias de cunho ginecológico e osteoartrites, seu sítio de ação se dar pela inibição da formação do septo e síntese da parede celular, bloqueando a transpeptidação terminal da biossíntese do peptidoglicano da parede celular (MENEZES CP, 2014; MELO VV, et al., 2012). Seus principais usos no estudo foram na intervenção contra pneumonias e sepses assim como no estudo de Menezes CP (2014). 
A respeito dos diagnósticos para prescrição, as sepses, de todos os focos, foram as mais encontradas. Diagnósticos como: Doença Pulmonar Obstrutiva Crônica (DPOC), Pós-operatório (PO), Infecção do Trato Urinário (ITU), etc., foram agrupados em um só grupo. Obtiveram-se também números relevantes das pneumonias, e ainda há um percentual relativamente alto a prescrições sem nenhum diagnóstico (Tabela 2).

Tabela 2 - Apresentação das infecções tratadas com antibioticoterapia na UTI Adulto em um hospital de referência cirúrgica do Maranhão, no período de dezembro de 2016 a janeiro de 2018.

\begin{tabular}{cc}
\hline INFECÇÕES & $\%$ \\
\hline Sepses & 38 \\
Outros & 32 \\
Pneumonias & 26 \\
Sem diagnósticos & 4 \\
TOTAL & 100 \\
\hline
\end{tabular}

Fonte: Lima Júnior FA, et al., 2019.

A Clindamicina, da classe das lincosamidas, mostrou variedade em sua utilização. O medicamento foi prescrito no tratamento de problemas como: DPOC com infecção, sepses, pneumonias, abscesso cervical, pé diabético, celulite cervical, dentre outros, apresentando-se em grande rotatividade de diagnósticos.

O Metronidazol, da classe dos nitroimidazol, é conhecido por sua atividade antiprotozoária. Ele opera na diminuição de grupos nitro na bactéria, formando metabólitos tóxicos que acabam rompendo o Ácido Desoxirribonucleico - (DNA) bacteriano (MELO VV, et al., 2012). No estudo, apresentou uso elevado em tratamentos como sepses, além de SD Fournier e pós-operatórios. O Levofloxacino foi o antibiótico mais utilizado no tratamento de PAC, sendo prescrito em $33,3 \%$ das vezes nos 9 casos diagnosticados.

Com ação bactericida, o Sulfato de Polimixina, tem seu principal uso em infecções graves por bactérias resistentes a alternativas menos tóxicas, em especial, as causadas por Pseudomonas aeruginosa e Acinetobacter (MELO VV, et al., 2012). No estudo, a Polimixina foi bastante utilizada no tratamento de pneumonias associadas a acineto multirresistente, demonstrando focos de resistência bacteriana na UTI do hospital em questão.

O Fluconazol, pertencente à classe dos antifúngicos, está na $11^{\circ}$ posição dos antibióticos mais prescritos. Tem o principal uso em candidemia, candidíase orofaríngea, esofágica, além de meningite criptocócica, dermatofitoses superficiais, entre outros (MELO VV, et al., 2012). Na pesquisa, o medicamento teve seu maior uso no tratamento de sepses.

A Oxacilina Sódica tem ação bactericida, sendo muito utilizada em infecções causadas por Staphylococcus sp resistentes a penicilina (MELO VV, et al., 2012). No presente estudo, o antibiótico foi pouco utilizado, estando em apenas 6 prescrições das 574 , onde 1 foi para caso sem diagnóstico.

O Cloridrato de Ciprofloxacino faz parte da classe dos Quinolonas. Seu uso habitual encontra-se para tratamentos de infecções de trato urinário em complicação, envolvendo bactérias gram-negativas resistentes, como Pseudomonas aeruginosa, prostatite bacteriana crônica, dentre outros (MELO VV, et al., 2012). No estudo, o medicamento teve seu principal uso no tratamento de ITU.

A Ceftazidima faz parte da classe de Cafalosporinas da $3^{\circ}$ geração, e é utilizada para tratamento de pneumonias, infecções urinárias, meningites e infecções intra-abdominais quando em associação a anaerobicidas (MELO VV, et al., 2012). Na pesquisa, ela foi prescrita para PO cesareana e laparotomia, pseudomonas na SEC traqueal e pneumonia. 
Gentamicina é o aminoglicosídeo escolhido em situações nas quais as instituições têm baixas taxas de resistência dos gram-negativos, utilizada bastante em associação, como ampicilina, penicilina e vancomicina (MELO VV, et al., 2012). Teve seu uso restrito ao tratamento de endocardite.

Os menos utilizados foram: Ampicilina Sódica, prescrita para o tratamento de ITU e para outro sem diagnóstico; Neomicina + Bacitracina, usada para erisipela em bolsa escrotal e para úlcera de decúbito; Cloranfenicol, do grupo de Anfenicois, foi manuseado no estudo em associação a Colagenase no tratamento de úlcera de decúbito e infecções de partes moles; Sulfametoxazol + Trimetoprin, do grupo das Sulfonamidas, empregue na terapêutica de PAC e pneumonia intersticial difisa; Cefalotina, a última do estudo do grupo das Cefalosporinas, teve apenas 2 prescrições para PO histerectomia complicada e sepse pulmonar; Azitromicina, única do grupo Macrolídeo, aplicada na terapêutica de pneumonia.

\section{CONCLUSÃO}

Nota-se ser de suma importância o saber a respeito do uso de antibióticos, visto que esses exercem ampla atuação nas unidades hospitalares, em especial as unidades de terapia intensiva sendo interligada diretamente a resistência bacteriana que é um atual problema de saúde pública a nível mundial, para tanto, no presente estudo, as sepses tiveram sua incidência em número alarmante, mostrando que infecções hospitalares são cada vez mais presentes. Fazendo-se necessário, portanto, conhecer o local de atuação, sua epidemiologia e o perfil microbiológico mais presente, para que assim sejam estabelecidas estratégias eficientes no uso inteligente dos antibióticos. Deixa-se para os próximos estudos a relação da prescrição de antibióticos com o resultado do antibiograma, assim, observando a eficiência ou não de tal prescrição no tratamento.

\section{REFERÊNCIAS}

1. ANVISA Agência Nacional De Vigilância Sanitária. Diretriz Nacional para Elaboração de Programa de Gerenciamento do Uso de Antimicrobianos em Serviços de Saúde. 2017.

2. COSTA ALP, SILVA JUNIOR ACS. Resistência bacteriana aos antibióticos e Saúde Pública: uma breve revisão de literatura. Estação Científica, Macapá, v. 7, n. 2, p. 45-57, maio/ago. 2017.

3. FERREIRA VM, et al. Perfil de dispensação de antibióticos nos ambientes ambulatorial e hospitalar em Montes Claros, MG. Revista Unimontes Científica, Montes Claros, v. 18, n. 1, p. 56-63, jan./jun. 2016.

4. MELO VV, et al. Guia de Antimicrobianos - 1.ed. - Goiânia, 2012.

5. MENEZES CP. Estudo da Utilização de piperacilina sódica + tazobactam em Unidade de Tratamento Intensivo Adulto de um Hospital Privado de Porto Alegre. Monografia (Monografia de Farmácia) - Universidade Federal do Rio Grande do Sul UFRGS. Porto Alegre, 2010

6. NEVES C, COLET C. Perfil de uso de antimicrobianos e suas interações medicamentosas em uma UTI adulto do Rio Grande do Sul. Revista de Epidemiologia e Controle de Infecção, Santa Cruz do Sul, v. 5, n. 2, p. 65-71, abr. 2015.

7. PAYNE LE, et al. Cefepime-induced neurotoxicity: a systematic review. Critical Care. 2017.

8. PINTO IC, et al. Eficácia dos antibióticos: a percepção do usuário das regiões do Vale do Ave e de Aveiro. XIII Congresso de Associação Portuguesa de Epidemiologia, XXXVI Reunión Científica de la SEE de 11 a 14 de setembro de 2018. Lisboa.

9. SANTOS RG, et al. Prescrições de antimicrobianos de uso restrito de pacientes internados em um hospital de ensino. Rev. Bras. Farm. Hosp. Serv. Saúde, São Paulo, v.7, n.1, p. 8-12, jan./mar. 2016.

10. SILVA CDR, SILVA JUNIOR M. Estratégias para uso adequado de antibióticos em unidade de terapia intensiva. Einstein (São Paulo), São Paulo, v. 13, n. 3, p. 448-453, set. 2015.

11. SILVA TFA, et al. MECANISMO DE AÇÃO, EFEITOS FARMACOLÓGICOS E REAÇÕES ADVERSAS DA CEFTRIAXONA: Uma revisão de Literatura. Revista Eletrônica de Farmácia. Vol. XI (3) 48-57, 2014. 